\title{
Erratum to: Genome-wide analysis of an avirulent strain that induces protective immunity against challenge with virulent Streptococcus Suis serotype 2
}

Jing Wang ${ }^{1 *+}$, Youjun Feng ${ }^{2+}$, Changjun Wang ${ }^{3}$, Feng Zheng ${ }^{3}$, Bachar Hassan ${ }^{4}$, Liming Zhi ${ }^{1}$, Wenjuan Li ${ }^{1}$, Yi Yao ${ }^{1}$, Elaine $\mathrm{He}^{5}$, Shibo Jiang ${ }^{7}$ and Jiaqi Tang ${ }^{6^{*}}$

\section{Erratum}

After the publication of the original article [1], discrepancies were discovered in the title of the manuscript. The title of this manuscript should read "Genome-wide analysis of an avirulent strain that induces protective immunity against challenge with virulent Streptococcus suis serotype 2". This has now been acknowledged and corrected in this erratum.

\begin{abstract}
Author details
${ }^{1}$ Translational Medicine Center, PLA Hospital No. 454, Nanjing 210002, China. ${ }^{2}$ Department of Medical Microbiology and Parasitology, Zhejiang University School of Medicine, Zhejiang, Hangzhou 310058, China. ${ }^{3}$ Department of Epidemiology, Medicinal Research Institute, Nanjing Military Command, Nanjing 210002, China. ${ }^{4}$ University of North Carolina, Chapel Hill, NC, USA. ${ }^{5}$ The Warren Alpert Medical School of Brown University, RI02912, Providence, USA. ${ }^{6}$ PLA Research Institute of Clinical Laboratory Medicine, Nanjing General Hospital, Nanjing Military Command, Nanjing 210002, China. ${ }^{7}$ Lindsley F. Kimball Research Institute, New York Blood Center, New York, NY 10065, USA.
\end{abstract}

Received: 27 June 2017 Accepted: 27 June 2017

Published online: 04 July 2017

\section{Reference}

1. Wang J, Feng Y, Wang C, Zheng F, Hassan B, Zhi L, Li W, Yao Y, He E, Jiang $\mathrm{S}$, Tang J. Genome-wide analysis of a avirulent and reveal the strain induces pro-tective immunity against challenge with virulent Streptococcus suis Serotype 2. BMC microbiology. 2017 Mar 14;17(1):67.

\footnotetext{
*Correspondence: wj6373@hotmail.com; tjq85@hotmail.com ${ }^{\dagger}$ Equal contributors

${ }^{1}$ Translational Medicine Center, PLA Hospital No. 454, Nanjing 210002, China ${ }^{6}$ PLA Research Institute of Clinical Laboratory Medicine, Nanjing General Hospital, Nanjing Military Command, Nanjing 210002, China

Full list of author information is available at the end of the article
}

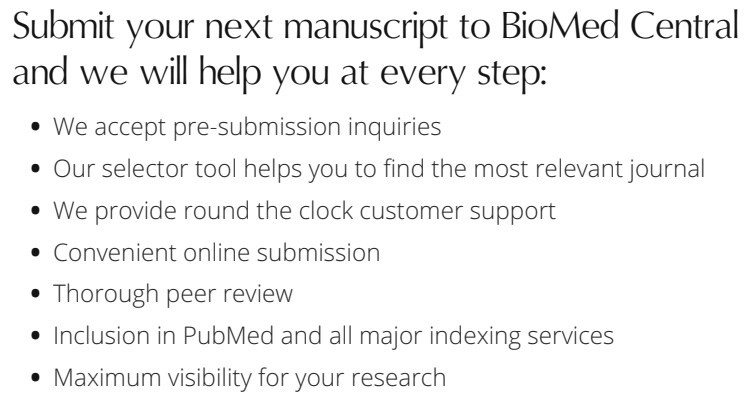
and we will help you at every step:

- We accept pre-submission inquiries

- Our selector tool helps you to find the most relevant journal

- We provide round the clock customer support

- Convenient online submission

- Thorough peer review

- Inclusion in PubMed and all major indexing services

- Maximum visibility for your research

Submit your manuscript at www.biomedcentral.com/submit 